\title{
PSYCHIATRIE: EEN AMBACHT TER DISCUSSIE Historiciteit en subject in de definitie van het psychiatrisch veld
}

\author{
Hubert Van Hoorde
}

Car l'exactitude se distingue de la vérité, et la conjecture n'exclut pas la rigueur.

Jacques Lacan (1966 [1953])

\section{Inleiding}

De vraag naar de ontologische status van de psychiatrie is niet nieuw. Dit betekent daarom niet dat men haar zonder meer terzijde kan schuiven. Merkwaardig genoeg ontbreekt in vele handboeken een definitie van de psychiatrie en van haar werkveld.

Is de psychiatrie als zodanig wel te definiëren? De vraag dringt zich op en herneemt een vroegere vraag, die een oudere collega - als assistent in opleiding was dit overigens een gezonde confrontatie - mij twintig jaár geleden toevoegde op de hem eigen, schertsende wijze: "Van Hoorde, psychiatrie, bestaat dat eigenlijk wel?" Mijn eerste reactie was toen achteraf bekeken gefundeerd in de latente idee van het ambacht. Men kon, zo was het antwoord, moeilijk ontkennen waar men mee bezig was. Maar daarenboven leefde bij mij de latente overtuiging dat deze ambachtelijke benadering geschraagd werd door een theoretisch kader waarvan de volledigheid toen nog moest en zou ontdekt worden naarmate de opleiding terzake vorderde. Wat toen werd gevraagd, was helemaal niet zo grappig als het klonk. Wellicht was het zelfs de verzuchting van iemand die de verbrokkeling van zijn werkveld aanvoelde. Dit werkveld heet in Vlaanderen vijfentwintig jaar later overigens nog altijd officieel 'neuro-psychiatrie', een term waaraan onderhavige discussie voorbijgaat.

In voorliggende tekst poog ik de noodzakelijke elementen voor een definitie van het psychiatrisch veld te verzamelen. Het spreekt vanzelf - ook al miskent de medische professie dit wel vaker - dat deze elementen niet alle van strikt medische aard kunnen zijn.

\section{Geschiedenis en 'hystorie'}

In een nog steeds noodzakelijk blijvende poging de psychiatrie als 
theoretisch corpus en als praxis wetenschappelijk te funderen kan men niet om de geschiedenis van deze discipline heen. De hedendaagse tendens is de geschiedenis te vergeten, de ontstaansvoorwaarden en prille evolutie van een gevestigde wetenschap te verdringen (Foucault 1971). Daarbij vergeet men gemakshalve welke rol de groepsvorming speelt voor het vestigen van een wetenschappelijke discipline (Stengers 1992). Deze tendens geldt niet alleen voor de psychiatrie, maar is in de wetenschappen vrij algemeen. Hij geeft aanleiding tot het opstellen van een overtrokken roze beeld waarin zowel de noodzaak van de ontdekking als de subjectieve implicatie van de ontdekker onder de breuklijn van de verdringing vallen en als onbelangrijk of zelfs onbestaande worden afgedaan. De al te roze tint ligt precies in de ontkenning van het voorafgaand weten en de verheerlijking van het actuele als alleen geldig. Vooruitgang op wetenschappelijk gebied lijkt in deze ideologische voorstelling een lineair proces waarin radicale breuklijnen een gradus van stijgende trappen gestalte geven. Dat men nieuwe antwoorden vindt of construeert, staat buiten kijf. De noodzaak is evenwel eerder nog de juiste vragen te stellen bij gevonden antwoorden. Hoe kwam men er toe precies die terreinen te onderzoeken en dus te vinden wat men (soms niet) zocht? De subjectieve implicatie is nog complexer: in een meesterpositie kan men ontwerpen, ontdekken en een theorie opbouwen om nadien het verworven weten mee te delen. Wanneer de initiële meester verdwijnt en anderen het opgebouwde weten verder doorgeven, ontstaat een andere verhouding tot het weten en de wijze waarop het ter sprake wordt gebracht. Dit heeft voor de psychiatrie effecten op haar praxis.

Om deze misschien al te kernachtig geformuleerde uitspraken te adstrueren zal ik verder in dit artikel refereren aan de discourstheorie zoals Jacques Lacan (1991 [1969-1970]) deze heeft ontworpen evenals aan de theoretische inzichten in de ontwikkeling van de psychiatrie die zij toelaat. Zo zal ook blijken dat de theorie over het subject meer vandoen heeft met de geschiedenis van de psychiatrie zelf dan men heden pleegt te denken. De historie als verhaal over een diachronie is immers verbonden met de historiciteit als existentieel gegeven voor het spreekwezen, met name het subject dat in zijn oorspronkelijk discours de hysterische positie inneemt: vandaar de metaforische verknoping in 'hystorie'. Overigens is de conceptualisering van het subject zelf in de filosofie (Couloubaritsis 1990) en per extensie in wat des mensen is en aan de psychiatrie raakt of waarop deze laatste gegrondvest is, al geen eenvoudige zaak. Op deze discussie kan ik hier uiteraard niet ingaan, zij overschrijdt het bestek van dit artikel.

Een eerste stelling is nu dat de psychiatrie steeds een praxis van het woord is geweest. Zij blijft dit ook, zelfs met de ontwikkelingen die zich in 
haar werkveld aftekenen en waarvan men op het eerste gezicht meent te kunnen aannemen dat zij zich buiten het woord situeren (Silvestre 1987, Van Hoorde 1992).

\section{De praxis van het woord en haar theoretische gronden}

Als praxis van het woord is de psychiatrie een klinische wetenschap die tot stand kwam in chronologisch en in ideologisch verband met het ontstaan van de moderne geneeskunde. Michel Foucault (1963) heeft deze evolutie en de epistemologische sprong die in de tweede helft van de achttiende eeuw plaatsgreep, op indringende wijze beschreven. Ik verwijs hiervoor naar zijn magistraal Naissance de la clinique.

Het ontstaan van de moderne medische kliniek als kliniek van de blik laat het subject achter met zijn gedeeldheid die geen onderwerp van deze kliniek is. Deze moderne kliniek laat in haar demarche toe uit de particuliere casus algemene wetmatigheden af te leiden. $\mathrm{Zij}$ steunt in grote mate op de nauwgezette gevalsbeschrijving. Ook de psychiatrie vertrekt van deze premissen en neemt de nauwlettende observatie en de zorgvuldig opgestelde gevalsbeschrijvingen als steunpunt voor haar theoretische ontwikkeling (Pinel 1802). De psychiatrie past zich als praxis van het woord aan de medische kliniek aan, zodat het eenmaal vastgelegde verhaal van het subject als rest ter bewerking aangeboden wordt en blijft. Deze rest maakt de ontdekking van de psychoanalyse als matrix van de psychotherapie niet alleen mogelijk, maar ook noodzakelijk. Bewerkingen op het verhaal zonder rekening te houden met het onbewuste leiden immers alleen tot het ontwerpen van nieuwe descriptieve categorieën, waarvan de sensitieve betrekkingswaan als voorbeeld geldt (Kretschmer 1966 [?]). In wat hier een praxis van het woord heet, moet dat woord worden opgevat als de betekenaar zoals Lacan die in verbinding met de subjectwording theoretisch uitwerkte. Er zijn immers andere vormen van praxis van het woord - zoals de religieuze en de magische, waarbij de practicus betekenaars op het subject, c.q. op het lichaam aanbrengt - zodat het noodzakelijk is het onderscheid te maken tussen

a. de kliniek van het teken.

b. de kliniek met de betekenaar

c. de kliniek van de betekenaar

De psychiatrie lijdt ondanks haar maatschappelijke extensie en geprofessionaliseerde uitbouw in haar theoretisch corpus onder een verscheurdheid, die ontstaan is door en om der wille van de miskenning van haar centraal manco: het is onmogelijk de waarheid geheel uit te spreken, de exactheid van 
de wetenschap dekt de waarheid van het subject niet. Dit manco is inherent aan elke theorie en staat de bruikbaarheid ervan niet in de weg, tenzij precies daar waar men het poogt te negeren. Manco en waarheid raken elkaar dus (Lacan 1990 [1974]). De basis van elke discussie terzake ligt in de kliniek zoals de clinicus haar in de praxis ontmoet, wat zowel het ontwerpen als het toetsen van theoretische inzichten toelaat en noodzaakt.

Uitgaande van de stelling dat de psychiatrie altijd en overal een praxis van het woord is geweest, moet ik verder ingaan op de vraag welke status dit woord is toebedeeld. Als klinische discipline heeft de psychiatrie zich, zoals ik reeds aangaf, ontwikkeld tegen de achtergrond van de moderne medische kliniek waarop zij zich met haar particulariteit is komen inschrijven. Daarbij heeft zij dus een erfenis van haar antecedenten in filosofie, religie en magie meegedragen om deze in haar praxis te versmelten tot een min of meer gedoseerd amalgaam met de in toenemende mate verworven natuurwetenschappelijk gefundeerde kennis van de anatomische structuur en de fysiologische processen van het cerebrum. Dit amalgaam levert echter nooit een voldoende geïntegreerde legering op en blijft de kenmerken van zijn oorsprong in zich dragen onder de vorm van scheidingslijnen in de theoretische beschouwing en breukvlakken in de klinische praktijk. De inbedding van de psychiatrie in de moderne medische kliniek, die in essentie een kliniek van de blik is, levert een rest op: het verhaal van het subject, dat op diverse manieren aan bod komt, maar dat veelal het voorwerp is van objectiverende reducties. Op grond van deze reducties blijft het verhaal als rest door het subject aangeboden in een constante verschuiving op zoek naar de 'luisterende genezer' (Jackson 1992). Dit aanbod heeft op zijn beurt geleid tot de ontdekking van het onbewuste en de ontwikkeling van de psychoanalyse. Deze ontwikkeling is in die zin onontkoombaar dat zij zich steeds voor iedere particuliere casus herhaalt, zij het dat de individuele lotgevallen uiteraard hun eigen beloop kennen. Bij deze stelling acht ik de diagnostische categorie van ondergeschikt belang: men moet niet denken dat dit enkel opgaat voor het neurotisch subject. Wie met de praktijk vertrouwd is, weet dat ook psychotici de zelfde zoektocht maken, hoe zeer dit ook in wetenschappelijke middens soms wordt ontkend. Dit is overigens een belangrijk argument om de praktijkervaring te staven dat een psychoticus meer dan medicijnen nodig heeft. Waar dit voor neurotische klachten als evident wordt aangenomen, lijkt het er in de actuele maatschappelijke ontwikkeling nochtans vaak op dat men liever deze wetenschap verdringt op grond van de hypothese dat een biologische stoornis niet alleen de noodzakelijke, maar meteen ook de voldoende voorwaarde voor een psychose is. Daarbij bewijst men enige lippendienst aan het zogenaamd 'bio-psycho-sociaal model' zonder dat dit gevolgen heeft (Van den Hoofdak- 
ker 1995). De tweede hypothese is immers dat de farmaceutische aanpak niet alleen vaak noodzakelijk is - wat ik niet betwist! -, maar ook meestal een voldoende antwoord oplevert. Met dit laatste kan ik het zeker niet eens zijn, zowel op theoretische gronden als op grond van klinische ervaring.

Daarbij wil ik ook een lans breken voor de heden ten dage onderschatte waarde van de gevalsstudie in de psychiatrie aan de hand van het feit dat een casus, de zogenaamde 'casus $\mathbf{N}=1$ ', toelaat een kennisveld te ordenen en algemene wetmatigheden van structurele aard te formuleren die verder onderzoek mogelijk maken (Platteau 1982, Mooij 1988). Deze demarche is van een andere aard dan die welke zich richt op het kwantitatief onderzoeken van een feit aan de hand van patiëntencohorten. Bij de gevalsstudie gaat het om het bestuderen van samenhangen, terwijl de kwantificering eerder op het statistisch onderzoek van de spreiding van een kenmerk is gericht. Waar het op aankomt is niet de ene methode boven de andere te stellen, maar er op te wijzen dat zij wezenlijk van elkaar verschillen door de onderscheiden aard van de gegevens die zij opleveren: zij hebben elk naast elkaar hun waarde en zijn in wezen niet vergelijkbaar aangezien zij op een verschillend kennisveld opereren (Van Hoorde 1986). Als waarschuwing geldt daarbij dat men te makkelijk alle krediet aan de kwantificering geeft waar men het aan de gevalsstudie heeft ontnomen, dit laatste dan mijns inziens geheel ten onrechte. Deze vaststelling sluit nauw aan bij wat ik in de vorige paragraaf aanbracht.

De inzichten in het ontstaan van de moderne medische kliniek - waarvoor ik eerder verwees naar de essentiële studie van Foucault - moet ik aanvullen met de betekenaar als concept en met een nieuwe conceptualisering van de notie van discours, die meer van structurele aard is dan deze van Foucault, en die Lacan ons heeft aangereikt.

De oude kliniek van de essentie der ziekten, van de vooraf gegeven en onwrikbare theorie, van mysterieuze principes en invloeden is een kliniek met de betekenaar: dit wil zeggen dat zij geen kliniek van het teken is in de zin van de moderne medische kliniek, maar een kliniek die werkt met woorden, wat er nog geen kliniek van de betekenaar van maakt. Zodoende rijst onmiddellijk een essentieel punt op: vóór de intrede van de moderne kliniek gaat het om de betekenaar van de theorie, om de betekenaar die de arts op de patiënt aanbrengt, waarmee hij hem zoekt te merken (Van Hoorde 1992). Als voorbeeld geldt de dolkomische en tegelijk bittere beschrijving van het medisch corps door Molière. De moderne tegenhanger hiervan zijn bekende 'diagnostische' uitspraken zoals 'het zijn de zenuwen' en het welig tieren van in de mode wisselende diagnoses (hyperventilatie, hyperkinetisch syndroom, chronisch vermoeidheidssyndroom en tutti quanti) in de medische rubrieken van bepaalde tijdschriften. 
Wanneer de moderne medische kliniek haar intrede doet, ontstaat een kliniek van het teken, van de indices. De hele negentiende eeuw is er van doordesemd. Deze ontwikkeling - die zo vruchtbaar is geweest voor de geneeskunde - herinnert er uiteraard aan dat de blik moet gestuurd worden door het onderscheidingsvermogen voor wat men moet zien (Silvestre 1987). Parallel blijft een rest achter die vraagt om herinschakeling in de betekenende keten: de psychiatrische kliniek gaat zich daarmee gelasten en een gooi doen naar een kliniek van de subjectieve factor. Tot zij echter op haar beurt zelf bijvoorbeeld met de semiologie van de persoonlijkheidsstoornissen - een kliniek van het teken, van de blik en sluipend een kliniek van de sociale norm wordt.

Op dat ogenblik ontstaat terug een rest zodat de psychoanalyse als het ware noodgedwongen ten tonele verschijnt om gestalte te geven aan een theorie die een kliniek van de betekenaar schraagt. Het gaat er met name om de sleutelbetekenaars in het verhaal terug te vinden, die de subjectieve positie stutten en de weg naar het grondend fantasma wijzen. De psychoanalyse, de door Sigmund Freud ontworpen discipline, onderscheidt drie niveaus: de onderzoeksmethode, de behandelingsmethode en het geheel van theorieën omtrent het psychisch functioneren, het weze op psychologisch of op psychopathologisch vlak. Haar centrale ontdekking is die van het onbewuste en van de overdracht; de drifttheorie en de status van het object zijn er niet uit weg te denken. Verder bouwend op die grondslagen werkte Jacques Lacan de theorisering van het gedeeld subject, van de betekenaar en de discourstheorie uit terwijl hij de theorie van het object verder aanscherpte met zijn ontdekking van het object $a$ en de formalisering van het fantasma.

Het belang van Jacques Lacan is dat hij van in de jaren vijftig is doorgestoten naar epistemologische vragen rond de psychoanalyse en per extensie de psychiatrie, onder meer door het invoeren van concepten uit de linguïstiek. De effecten van dit ontwerp op de klinische praxis zowel als op de cultuur zijn onmiskenbaar.

Drie posities worden hier dus samenvattend uitgetekend. Het spel begint met een kliniek met de betekenaar. Deze loopt stuk en kantelt in een kliniek van het teken. De kliniek van het teken blijft in de psychiatrie een stroming bijhouden die zich van de betekenaar bedient doch, deze niet theoretiseert en als aanvulling een kliniek van de subjectieve ziektegeschiedenis oplevert, waarvan bij voorbeeld Stolk (1975) schitterende voorbeelden geeft. Deze laatste kliniek moet kantelen naar een kliniek van de betekenaar die bij haar theoretische kanteling in de psychoanalyse haar functie als wetenschap van het subject kan opnemen. 


\section{Van symptoom, substraat en de discourstheorie}

Het onderscheid tussen de medische opvatting van het symptoom als teken en de psychoanalytische opvatting ervan als symbolische constructie duidt een fundamentele breuk aan in het psychiatrisch werkveld (Van Hoorde 1996). Beide werkwijzen bewegen zich op een verschillend kennisveld. Deze vaststelling leidt tot de invoering van een beschouwing over het substraat en zijn status in de psychiatrie. Het psychisch apparaat is ondenkbaar zonder biologisch, somatisch substraat; de stoornissen, zowel anatomisch als fysiologisch, van het somatisch substraat worden op psychisch niveau vertaald in psychische stoornissen; niet heel de psychische stoornis op zich en niet alle psychische stoornissen zijn evenwel herleidbaar tot dezelfde logica. Waar het gaat om de positie van het subject en zijn lijden, is de betekenaar het substraat par excellence. Het benaderen van deze structurele problematiek vereist dat men rekening houde met het onbewuste als correlaat van de inbedding van het subject in de symbolische orde, waarvan de taal de voorwaarde is.

Is de eerste vaststelling dat de psychiatrie een praxis van het woord is, dan moet ik uit wat voorafgaat de tweede vaststelling afleiden, met name dat de psychiater in zijn werk- en observatieveld geïmpliceerd is. Elke 'wetenschappelijke observatie' zal in de psychiatrie steeds een onmiskenbare - maar zo vaak miskende! - invloed hebben op het zogenaamd geobserveerde. Het colloque singulier tussen patiënt en psychiater is immers een veld van krachtlijnen die door de overdracht worden geïnstalleerd. Het hoeft ons niet te verwonderen dat men krampachtig poogt de psychiatrische bedrijvigheid te objectiveren en te kwantificeren: het is de angst van de wetenschapper voor zijn vermeend object - de andere (mens) - die hem drijft tot het optrekken van een afscherming die in dit geval de vermomming van natuurwetenschap aanneemt. Om dit beter te verduidelijken moet ik een beroep doen op Lacans discourstheorie.

Deze theorie werd door Jacques Lacan geformaliseerd met een stel van vier termen : het subject $\$$, doorstreept omdat het door de taal gedeeld is en er tegelijk door wordt geconstitueerd zoals het oprijst in de keten van betekenaars $\mathrm{S}_{2}$, ingesteld door de meesterbetekenaar $\mathrm{S}_{1}$. De deling van het subject constitueert in dezelfde beweging het object $a$ als rest van de gedeeldheid door de taal, rest die uit het discours valt en achterblijft als zich nooit materialiserende oorzaak van verlangen. Wat valt, reëel - in het reële ook - valt, komt hier meteen langs een associatie met de anale sfeer de vier objecten invoeren: de borst, de faeces, de stem en de blik.

Het discursief spel heeft dus vier potentiële acteurs $\left(\$ \rightarrow S_{1} \rightarrow S_{2} \rightarrow a\right)$ 
die in hun vaste sequens over vier posities roteren, namelijk

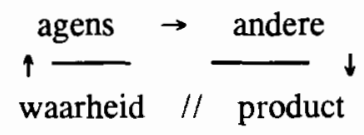

De uitgangspositie is het makkelijkst aan te geven met de klacht van het subject dat zich tot de ander richt met een vraag

$$
\$ \rightarrow S_{1}
$$

Het doel is daarbij de ander, in dit geval de meester, zijn weten te doen spuien ("dokter, wat heb ik?")

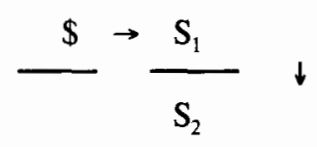

Daarbij blijft iets verborgen: het subject houdt zijn waarheid, waarvan het onbewust weet heeft, onder de breukstreep van de verdringing en meteen ook buiten schot voor het verzameld weten van de meester. Dit maakt op de onderste regel van de formule een onmogelijkheid zichtbaar: de meester kan de waarheid van het subject niet vatten, zijn weten schiet tekort. Wanneer ik deze discoursformule vervolledig, tekent $\mathrm{zij}$ het hysterisch discours uit. Het subject klaagt, ondervraagt de meester en verlangt dat zijn weten de oplossing voor de klacht zou bieden. Het object van verlangen blijft echter buiten schot, de meester faalt noodgedwongen omdat hij niets over de waarheid van het subject kan zeggen en wordt daarop van zijn voetstuk gestoten waarop het subject hem door een nieuwe meester kan vervangen:

$$
\uparrow \frac{\$}{a} \| \frac{\mathrm{S}_{1}}{\mathrm{~S}_{2}} \downarrow
$$

Het belang van een dergelijke formalisering is dat zij toelaat te bepalen vanuit welke positie iemand spreekt, het woord neemt en welke gevolgen (het product) dit spreken zal (kunnen) hebben. Het gaat hierbij uiteraard niet om algebraïsche 'formules', maar om het uittekenen van een structuur met vier operatoren die Lacan door rotatie met behoud van de volgorde tot het opstellen vier verschillende discours bracht: 
* bij het meester-discours

$$
\uparrow \frac{S_{1}}{\$ / /} \rightarrow \frac{S_{2}}{a} \downarrow
$$

is het product een object, men denke aan de diagnostiek die de patiënt in wezen objectiveert;

* in het hysterisch discours

$$
\uparrow \frac{\$}{a / /} \rightarrow \frac{\mathrm{S}_{1}}{\mathrm{~S}_{2}}
$$

wordt de meester door het subject als zodanig geïnstalleerd (de overdracht) om zijn weten te spuien - wie doceert kent het scherp van deze snede;

* door het analytisch discours

$$
\uparrow \frac{a}{\mathrm{~S}_{2}} \rightarrow \frac{\$}{\mathrm{~S}_{1}}
$$

kan de analyticus zich als object - niet als persoon - voor de overdracht laten gebruiken om het subject tot de productie van zijn meesterbetekenaar de sleutel van de neurose - te brengen;

* tot slot laat het universitair discours zien

$$
\uparrow \frac{S_{2}}{S_{1}} \rightarrow \frac{a}{\$} \downarrow
$$

hoe de oorspronkelijke meester met zijn ontdekking is verdrongen en het weten als een herhaling wordt doorgegeven. De ander is in deze opstelling gereduceerd tot een object van de pedagogie en blijft achter als gedeeld subject dat zich afvraagt wat het met het weten kan of moet aanvangen. Wie school heeft gelopen, herkent in deze structuur ongetwijfeld iets.

Toegepast op de psychiatrie wil ik uitgaande van de theorie der discours 
stellen dat het invoeren van een weten vanuit de keten der betekenaars, $S_{2}$, voor de patiënt zou betekenen dat een nieuwe betekenaar op zijn lijden wordt geplakt en dat hij zo opnieuw op een objectiverend parcours zou worden gestuwd dat naar de metonymische oneindigheid leidt. In de plaats van de medicalisering zou dan sprake zijn van psychologisering van zijn klacht, waarbij het model van de kliniek met de betekenaar evengoed van kracht zou zijn (Verhaeghe 1991). De invalshoek van de betekenis levert dus niets op, evenmin als die van het geconstitueerd weten (Lacan 1991 [1969-1970]). Daarbij mogen we niet over het hoofd zien dat de posities in het discours de modaliteiten van de onontkoombare overdracht uittekenen: de kliniek van de betekenaar is een kliniek onder overdracht, wat het object $a$ in het analytisch discours voorstelt.

\section{Reductionisme en universele kliniek}

De universalisering van de kliniek van het teken voor het gehele klinisch veld van de psychiatrie getuigt in wezen niet alleen van reductionisme, maar is bovendien een totalitaire demarche terwijl de kliniek van de betekenaar de subjectieve particulariteit eerbiedigt, ook al stuit ze zelf op universele structuren (neurose, psychose, perversie). Het belang van de levensloop, van het levensverhaal - als verhaal veeleer dan als een aaneenrijgen van disparate 'life events' - voor de psychiatrie als medisch-therapeutische discipline zowel als voor haar wetenschappelijke fundering is derhalve onschatbaar. Het gaat er immers om in dit levensverhaal aan de hand van naar voren tredende betekenaars de symptoomvorming en de constructie van het sturend fantasma op te sporen. Wat van een andere orde is dan de demarche die zich bezighoudt met rubriceren en repertoriëren, waarmee ik onder meer naar het DSM-systeem verwijs. Dit voert meteen tot het aanduiden van het fundamenteel verschil met de biologische psychiatrie die zich tot volkomen legitiem project heeft gesteld de aard en de wijzigingen van het somatisch-cerebraal substraat te onderzoeken. Zij kan echter in genendele de gehele psychiatrie bestrijken, evenmin als wat hier gemakshalve de psychodynamische psychiatrie genoemd wordt, een voldoende samenhang kan uitwerken voor de hele psychiatrie. Het somatisch substraat is een noodzakelijke voorwaarde voor het psychisch functioneren daar is iedereen het uiteraard over eens -, maar het is geen voldoende voorwaarde om elke psychopathologie in haar beloop te betekenen of te verklaren. 
Is een definitie van de psychiatrie mogelijk?

Zo rijst de vraag naar een definitie van de psychiatrie als klinische wetenschap. De zoektocht naar deze definitie voert in de eerste plaats tot de vaststelling dat een verborgen paradigma heerst: het vakgebied blijkt veelal als bekend en omlijnd te worden beschouwd zonder dat men de epistemologische eisen klaar stelt, die het beoefenen en het theoretiseren van de psychiatrie sturen. Naast het medisch vertoog in de zin die Foucault hieraan gaf, wordt voor de psychiatrie als klinische en grotendeels ambachtelijk verworven wetenschap de psychoanalyse als onmisbaar referentiepunt aangevoerd aan de hand van de gevalsstudies en hun theoretische uitwerking: het bestek van dit artikel laat niet toe de casuïstiek uitgebreid te behandelen, daarvoor verwijs ik naar een vroegere publicatie (Van Hoorde 1992). Wat ongeacht de voorhanden zijnde diagnostische categorie - het weze een casus in het register van de neurose, de perversie of de psychose - we met 'analytisch luisteren en interveniëren' aanduiden, is in wezen een respectvol beoefenen van de kliniek van de betekenaar en van het object $a$ in analytische zin (Quackelbeen 1991). Deze kliniek heeft eveneens haar belang in het vetd van wat men tot voor kort de 'organische stoornissen' noemde, zij het dat zij daar hand in hand gaat met de medische kliniek van het teken.

Opvallend bij de lectuur van Psychiatrie I Inleiding van H.C. Rümke (1969) is dat hij geen afgeronde definitie van 'de' psychiatrie opstelt in tegenstelling met de psychologie, waarvan hij zegt: 'psychologie is de leer van het verhoudingsleven'. Zijn driedelig handboek is als het ware een doorlopende omschrijving van de psychiatrie vanuit zijn klinische ervaring. De theoretische achtergronden haalt hij niet alleen uit de neurofysiologie, de biologie en de algemene geneeskunde, maar ook uit de psychologie, de psychoanalyse en de filosofie. Zijn stelling dat de psychiatrie niet louter natuurwetenschappelijk is, gaat volgens hem ook op voor de geneeskunde. Deze laatste stelling vinden we trouwens terug bij de fenomenoloog Buytendijk (1984 [1965]). Henri Ey (1974) geeft een definitie op p. 66 van zijn handboek: "De psychiatrie is een tak van de geneeskunde die als object heeft de pathologie van het 'relatieleven' op het niveau van de integratie die de autonomie en de adaptatie van de mens bepaalt binnen zijn bestaansvoorwaarden". Waarop hij merkwaardig genoeg onmiddellijk aansluit met te zeggen wat psychiatrie allemaal niet is en te illustreren waarmee men ze zeker niet mag verwarren: psychologie, neurologie, sociologie. Het lijkt wel dat Ey vreest vaste grond te verliezen als hij zijn discipline - waarin hij nochtans een vooraanstaande, bijna koninklijke plaats bekleedt - van te dichtbij zou vermengen met wat nochtans inherent met haar verbonden is. Vreemd is dat hij op opvallende wijze de filosofie 
weglaat. Myre Sim (1974) gaat onmiddellijk van start zonder het terrein te definiëren, net zoals $C$. Jannes in het artikel waarmee deze zijn compilatiehandboek opent en zonder terreindefinitie van het oude Egypte naar de psychofarmacologie kruist. Dit hoeft niemand te verwonderen: het ontbreken van een definitie zoals bij andere medische specialismen die door hun actieterrein worden gedefinieerd, heeft immers te maken met de verbrokkeling van het psychiatrisch veld door zijn verschillende substraten.

De eerder geformuleerde overwegingen leiden tot volgende omschrijving van het psychiatrisch werkveld, waaraan ethische implicaties zijn verbonden en die een werkdefinitie aanreikt van de psychiatrie als klinische wetenschap.

Psychiatrie is als onderdeel van de geneeskunde een klinische wetenschap die zich bezighoudt met het psychisch lijden, waarin een weten ontwikkeld wordt vanuit en over een particuliere casus, dit in relatie tot algemene wetmatigheden. Zij is een praxis van het woord, ook als de psychiater zich laat bijstaan door andere technieken, en daarbij volgens de strenge principes van de medische kliniek te werk gaat. Deze principes leiden specifiek voor de psychiatrie tot een opdeling van haar klinisch veld: naast de kliniek van het teken, waarvan het substraat somatisch-fysiologisch is, geldt evenzeer de kliniek van de betekenaar, waarvan het substraat psychisch is, met name de betekenaar zelf. Voor een correct hanteren van beide klinische velden, het eerste zich vaak in en langs het tweede uitend, geldt dat het object van de psychiatrie het levensverhaal is. Het psychisch lijden is immers onontwarbaar verbonden met de condition humaine en het menselijk 'onbehagen' dat deel uitmaakt van de subjectwording. De asymmetrie tussen beide klinische velden tekent het centrale manco van de psychiatrie uit.

Als klinische wetenschap ontleent de psychiatrie haar bestaan aan haar manco, zoals het subject slechts subject kan zijn door de gedeeldheid die het tekent. Ieder reductionistisch en dus totalitair want desubjectiverend project zal het bestaan van de psychiatrie bedreigen. Dit geldt voor elke poging tot reductionisme, van welke signatuur zij ook weze. In ons tijdsgewricht komt de belangrijkste bedreiging echter uit de hoek van het zogenaamd biologisch denken wanneer de aanhangers hiervan, al dan niet met zoveel woorden, hun stellingen zonder aanvulling en voor het geheel van de klinische psychiatrie ongenuanceerd geldig achten.

\section{Besluit}

Vanuit de bescheidenheid van de klinische demarche grijpen we in dit artikel naar een project dat zich situeert op het vlak van de antropologische 
roeping van de psychiatrie. Het invoeren van de psychoanalyse in het psychiatrisch werkveld betekent immers niet dat een zoveelste hulpwetenschap wordt aangebracht, noch dat een bijkomende epistemologische stut onder het wankel bouwwerk wordt gezet. Het is de bedoeling de precieze architectuur van het gebouw na te trekken en deze terug te vinden door de uiteenzetting van de opdeling in kliniek van het teken, kliniek met de betekenaar en kliniek van de betekenaar. Deze nieuwe versnijding van het werkveld gaat verder dan de vroegere, eerder vage opdeling in een natuurwetenschappelijk en een hermeneutisch vlak waar zij de verrekening van de overdracht via de discourstheorie invoert in een veld dat hem tevergeefs langs de natuurwetenschap poogt uit te gommen. In wezen gaat het om de epistemologische eisen waaraan het correct beoefenen en theoretiseren van psychiatrie moet voldoen.

Deze onvolledige aanzet is een poging aan de ooit door een collega toegeworpen vraag of psychiatrie wel bestond, althans een eerste antwoord ter discussie te geven. Het is immers een soort 'Aha-Erlebnis' jaren na datum te merken dat ik uitging van een verkeerde assumptie, of eigenlijk van een presumptie: met name dat diverse auteurs wel allemaal hun afgeronde definitie van de psychiatrie uit voorraad kunnen leveren zonder dat men de bestelling lang van tevoren moet plaatsen, dat met name een te bereiken en bereikbaar punt bestond, waar het volledige weten omtrent de psychiatrie zich ophield. De vraag van de collega was, hoe schertsend ook gesteld, een duiding. Hebben duidingen overigens niet altijd een 'nachträglich' effect?

Gent, zomer 1996

\section{Literatuur}

Buytendijk, F.J.J. (1984 [1965]), Prolegomena van een antropologische fysiologie. Utrecht, Het Spectrum.

Couloubaritsis, L. (1990), La question du 'sujet' dans la philosophie grecque. In: Cahiers de l'Ecole des Sciences Philosophiques et Religieuses, 8-1990, pp. 9-41. Ey, H. (1974), Manuel de psychiatrie. Parijs, Masson.

Foucault, M. (1963), Naissance de la clinique. Parijs. Presses Universitaires de France.

Foucault, M. (1971), L'ordre du discours. Parijs, Gallimard.

Jackson, S.W. (1992), The Listening Healer in the History of Psychological Healing.

In: The American Journal of Psychiatry, 149:12, December 1992, pp. 1623-1632.

Jannes, C. \& M. Van Moffaert (1986), Psychiatrie. Gent. Omega Editions. 
Kretschmer, E. $\left(1950^{3}\right)$, Der Sensitive Beziehungswahn. Berlin.

Lacan, J. (1966 [1953]), Fonction et champ de la parole et du langage. In Ecrits (p. 286). Parijs, Editions du Seuil.

Lacan, J. (1990 [1974]), Televisie. Vertaling door J. Quackelbeen, Leuven/Amersfoort, Acco.

Lacan, J. (1991), Le séminaire Livre XVII (1969-1970) L'envers de la psychanalyse. Parijs, Editions du Seuil.

Mooij, A.W.M. (1988), De psychische realiteit - Over psychiatrie als wetenschap. Meppel, Boom-Amsterdam.

Pinel, $\mathrm{Ph}$. (1965 [an IX-1802]), Traité médico-philosophique sur l'aliénation mentale ou la manie. Parijs, fac simile Edit. Tchou.

Platteau, W. (1982), Een referentiekader voor de gevalsstudies van Freud. In Psychoanalytische Perspektieven, 2, pp. 11-183.

Quackelbeen, J. (1991), Zeven avonden met Jacques Lacan. Gent, Academia Press.

Rümke, H.C. (1969), Psychiatrie I Inleiding. Amsterdam, Scheltema \& Holkema.

Silvestre, M. (1987), Demain la psychanalyse. Parijs, Navarin (Diffusion Seuil).

Sim, M. (1974), Guide to Psychiatry. Edinburgh and London, Churchill Livingstone.

Stengers, I. (1992), La volonté de faire science. Les Empêcheurs de Penser en Rond, Parijs, Ulysse Diffusion.

Stolk, P.J. (1975), Een soort vuur. Amsterdam, Wetenschappelijke Uitgeverij.

Van den Hoofdakker, R.H. (1995), De mens als speelgoed. Houtem/Diegem Bohn Stafleu Van Loghum, en Utrecht/Antwerpen Kosmos-Z\&K Uitgevers.

Van Hoorde, H. (1986), 'Statistiatrie', nosologie en structuur: een vraag?. In Tijdschrift voor Psychiatrie, 1986/1, pp. 6-14.

Van Hoorde, H. (1992), Psychiatrie en psychoanalyse: scheiding van tafel en bank? Gent, Idesça.

Van Hoorde, H. (1996), La psychiatrie: un champ clinique en division. In European Psychiatry, Vol. 11/Suppl. 4, 1996, p. 399.

Verhaeghe, P. (1991), Klinische psychodiagnostiek vanuit de discourstheorie. Gent, Idesça. 